\title{
Gerze Horoz ve Tavuklarının (Gallus domesticus) Tunica Fibrosa Bulbi'si Üzerinde Anatomik, Histolojik ve Elektron Mikroskobik İncelemeler
}

\author{
Nazan GEZER iNCE ${ }^{1}$, Burcu ONUK ${ }^{2 *}$, Emel ALAN ${ }^{3}$, Sedef SELViler SizER ${ }^{2}$, Aydın ALAN $^{4}$, Murat \\ KABAK $^{2}$
}

\footnotetext{
${ }^{1}$ Istanbul Üniversitesi, Veteriner Fakültesi, Anatomi Anabilim Dalı, Avcılar, İstanbul, Türkiye.

${ }^{2}$ Ondokuz Mayıs Üniversitesi, Veteriner Fakültesi, Anatomi Anabilim Dalı, Samsun, Türkiye.

${ }^{3}$ Erciyes Üniversitesi, Veteriner Fakültesi, Histoloji Anabilim Dalı, Kayseri, Türkiye.

${ }^{4}$ Erciyes Üniversitesi, Veteriner Fakültesi, Anatomi Anabilim Dalı, Kayseri, Türkiye.
}

Özet: Bu çalışma Gerze horozu ve tavuğunda bulbus oculi'nin tunica fibrosa katmanının anatomik ve histolojik özelliklerinin ortaya konulması amacıyla yapılmıştır. Çalışmada 4 dişi ve 4 erkek olmak üzere toplam 8 adet kanatı kullanıldı. Orbita'dan çıkarılan toplam 16 adet bulbus oculi üzerinde makroanatomik, ışık ve elektron mikroskobik incelemeler yapıldı. Morfometrik ölçümler ile bulbus oculi'nin dikey elips bir görünüme sahip olduğu belirlendi. Işık mikroskobik incelemelerinde total olarak çıkarılan gözler \%10 formol-alkol solüsyonunda tespit edildi. Rutin histolojik işlemleri takiben $4 \mu \mathrm{m}$ kalınlığında alınan kesitlere genel yapıyı belirlemek için Crossman'ın triple boyaması uygulandı. Kan damarları içeren ve saydam olmayan sclera'nın anterior kısmında kemik plakların bulunduğu ve bu kısmın devamında sclera'yı çepeçevre hiyalin kıkırdağın desteklediği tespit edildi. Kubbe şeklinde olan cornea'nın ise damarsız ve saydam olduğu belirlendi.

Anahtar Kelimeler: Bulbus oculi, Cornea, Gerze tavuk ve horozu, Sclera.

\section{Anatomical, Histological and Electron Microscopic Studies on Tunica Fibrosa Bulbi of Gerze Rooster and Chickens (Gallus domesticus)}

\begin{abstract}
This study was carried out to determine the anatomical and histological features of the tunica fibrosa layer of bulbus oculi in Gerze rooster and chicken. A total of 8 animals including 4 females and 4 males were used in the study. Macroanatomic, light and electron microscopic examinations were carried out on 16 bulbus oculi taken from orbita. With morphometric measurements it was determined that the bulbus oculi has a vertical elliptical appearance. Eyes that were totally removed in light microscopic examinations were fixed in $10 \%$ formol-alcohol solution. Following routine histological procedures, Crossman's triple staining was performed to the sections taken $4 \mu \mathrm{m}$ thickness to determine general structure. In the anterior part of the non-transparent sclera with blood vessels, bone plaques were present and sclera was supported all around by hyaline cartilage in continuation. The dome-shaped cornea was determined to be without vessel and transparent.

Keywords: Bulbus oculi, Cornea, Gerze chicken and rooster, Sclera.
\end{abstract}

\section{Giriş}

Kanatlılar mükemmel çözünürlükte görüntü meydana getiren gözlere sahiptir ve bu nedenle görme duyuları çok gelişmiştir (Dursun ve Türkmenoğlu, 2002). Bulbus oculi'nin diğer memeli hayvanlara göre daha büyük şekillenmesi de bundan kaynaklanmaktadır ve türler arasında farklılık gösterir (King ve McLelland, 1984; Brooke ve ark., 1999). Bulbus oculi'nin duvarı dışarıdan içeriye doğru tunica fibrosa, tunica vasculosa ve tunica interna olmak üzere 3 tabakadan meydana gelmiştir (Dursun ve Türkmenoğlu, 2002). Tunica fibrosa'yı cornea ve sclera şekillendirmektedir. Cornea kuşlarda akomodasyonun sağlanmasında rol oynar ve cornea'nın konveks ve kıvrık yapı göstermesi odaklanmanın da o oranda güçlü olduğunun göstergesi olarak kabul edilir (Schaeffel ve Howland, 1987; Glasser ve ark., 1994). Sclera'da kanatlı hayvanlarda hiyalin kıkırdak ve kemik mevcuttur. Bu kemikler bir halka şeklinde düzenlenerek (FranzOdendaal, 2008) annulus ossicularis sclerae adını alır (Baumell ve ark., 1993). Bu yapılar bulbus oculi'nin dış duvarını şekillendirmekte ve memeli hayvanların sahip olduğu küre şeklindeki yapıdan farklı olarak kanatlı hayvanların bulbus oculi'sine oval ya da fincan benzeri bir form kazandırmaktadır (Nelson, 1942). Genel olarak bulbus oculi diurnal kuşlarda " küre veya yassı", nokturnal kuşlarda ise "tubuler" yapıdadır (King ve McLelland, 1984). Günümüze kadar göz; tavuk (Nelson,1942; Murphy ve ark., 1995; Shehan, 2012), kınalı keklik (Erdoğan 
ve ark., 2012 ), Brezilya kuşları (Lima ve ark., 2009 ), şahin (Gültiken ve ark., 2011) gibi kanatlı türünde anatomik ve histolojik olarak incelenmiştir. Çalışma materyalini ülkemizin yerel tavuk ırklarından bir tanesi olan Gerze Tavuk ve Horozları (Anonim, 2004) oluşturmuştur. Yapılan literatür taramalarında bu tavuk ırkı gözü ile ilgili anatomik bilgiye rastlanılmamış olmasından dolayı bu çalışma planlanmış, tunica fibrosa bulbi'sinin anatomik ve histolojik özelliklerinin ortaya konulması ve tavuk ırkları arasında farklılıkların olup olmadığının tespit edilmesi amaçlanmıştır.

\section{Materyal ve Metot}

Ondokuz Mayıs Üniversitesi Veteriner Fakültesi Anatomi Anabilim Dalı'nda daha önce yapılan çalışmalarda perfüzyon yöntemiyle tespit edilmiş olan 4 dişi ve 4 erkek olmak üzere toplam 8 adet Gerze tavuk ve horozu kullanıldı. Orbita'dan çıkarılan toplam 16 bulbus oculi'den 6 tanesi ışık mikroskobu, 4 tanesi taramalı elektron mikroskobunda (SEM), geriye kalan 6 tanesi ise makroanatomik incelemeler için kullanıldı. Morfometrik ölçümler bulbus oculi'nin axis bulbi externus ve equator bölgelerinden ve cornea'nın ise dorsoventral-mediolateral uzunlukları değerlendirilecek şekilde Mitutoyo dijital kumpas (Model CD-15D Mitutoyo Corporation, Japan) kullanılarak alındı. Işık mikroskobik incelemeler için orbita'dan total olarak çıkarılan bulbus oculi'ler \%10'luk formol-alkol tespit solüsyonunda 12 saat tespit edilmesinin ardından sırasıyla dereceli alkoller, metil benzoat ve benzol solüsyonlarından geçirilerek parafinde bloklandı. $\mathrm{Bu}$ parafin bloklardan Leica RM 2125 rotary mikrotomu ile $4 \mu \mathrm{m}$ kalınlığında alınan kesitlere genel yapıyı belirlemek için Crossman'ın üçlü boyama tekniği uygulandı (Crossman, 1937). Boyamanın ardından kesitler, BX51 Olympus; Tokyo, Japan marka fotoğraf ataçmanlı mikroskopta görüntülendi. Taramalı elektron mikroskop (SEM)'da incelenecek olan örnekler öncelikle 0,1 M (PH 7,4) PBS ile iki kez yıkandı ve sonrasında \%2,5'luk Gluteraldehit solüsyonunda 48 saat süre ile bekletildi. Daha sonra sıralı aseton serilerinden geçirilen dokulara CPD ile kurutma işlemi uygulanarak altın ile kaplandı. Örnekler taramalı elektron mikroskop altında çeşitli büyütmelerde (X200 - X10000) incelendi. Nomina Anatomica Avium (1993) kullanılarak isimlendirmeler yapıldı.

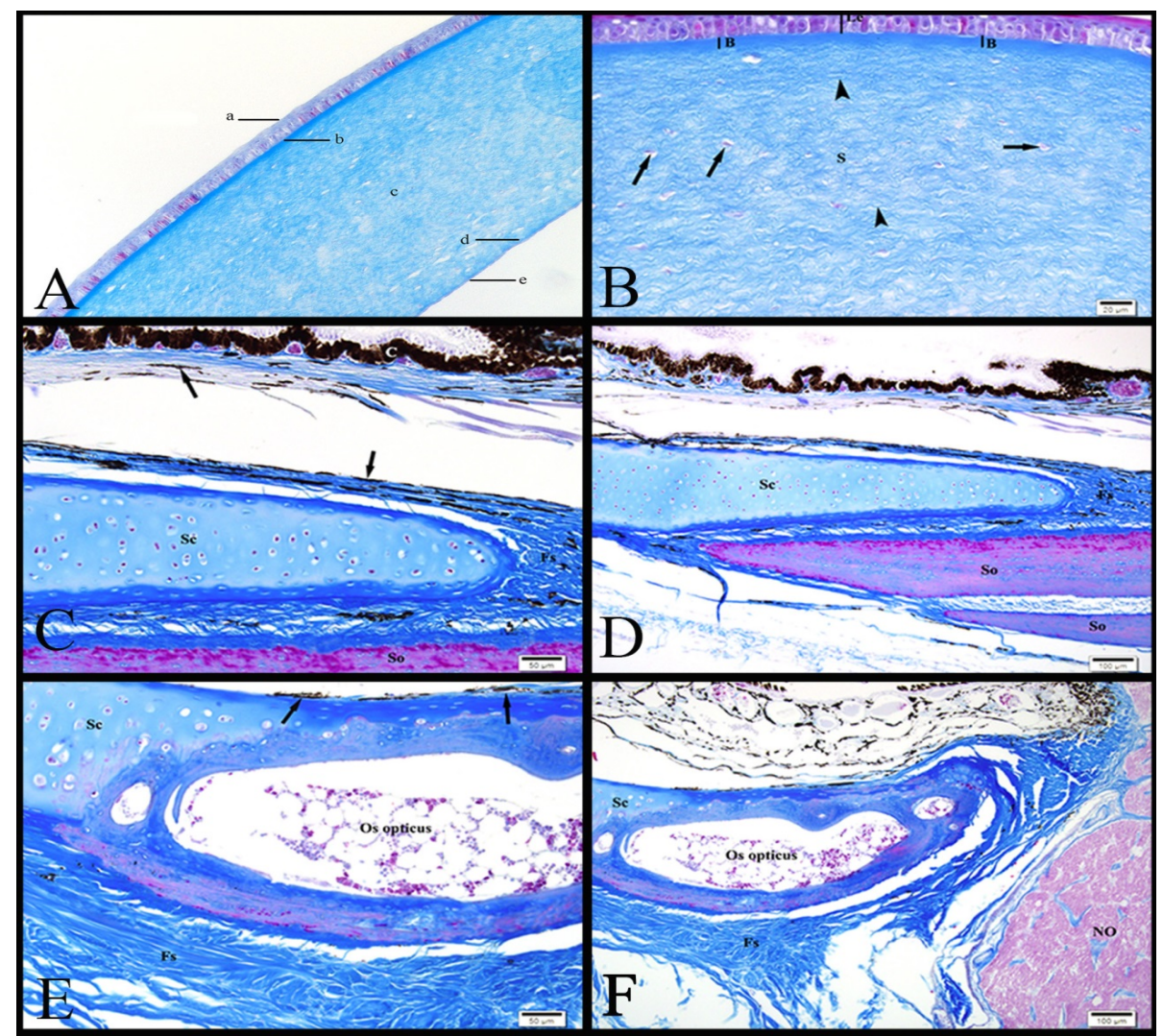

Şekil 1. Cornea (A-B) ve Sclera (C-D-E-F) katmanlarının histolojik yapısı. Çok katı ı yassı epitel (A: a, B: Le), Tek katlı yassı epitel katı (A: e), Bowman membranı (A: b, B: b), Stroma (A: c, B: s), Descement membran (A: d), lamina endothelium (A: e), keratoblastlar (B: ok), kollagen iplikler (B: ok başı). scleral kıkırdak (Sc), scleral kemik (So), fibröz sclera (Fs), melanositler (C: ok, E: ok) ve choroidea (C), nervus opticus (NO) 


\section{Bulgular}

Tunica fibrosa bulbi'nin saydam olan ve ön kısmını oluşturan cornea, sclera'nın devamı olup, konveks, renksiz ve damarsızdı. Cornea'nın dorsoventral uzunluğu dişide ortalama $9,02 \pm 050 \mathrm{~mm}$, erkekte $9,28 \pm 0,51 \mathrm{~mm}$; mediolateral uzunluğu ise dişide ortalama $9,05 \pm 0,63 \mathrm{~mm}$, erkekte $9,27 \pm 0,53 \mathrm{~mm}$ olarak ölçüldü. Bulbus oculi'nin ekvator uzunluğu dişide ortalama 17,04 $\pm 1,29 \mathrm{~mm}$, erkekte $17,43 \pm 0,35 \mathrm{~mm}$, axis bulbi externus uzunluğu ise dişide ortalama $13,87 \pm 0,88 \mathrm{~mm}$, erkekte $14,61 \pm 1,16 \mathrm{~mm}$ olarak belirlendi. Bulbus oculi'nin şekli morfometrik ölçümler doğrultusunda dikey elips olarak tespit edildi.

Mikroskobik olarak dıştan içe doğru 5 katmandan oluştuğu gözlendi (Şekil 1A-B). Corneanın en dış katmanı (lamina epithelialis, epithelium anterius corneae) çok katlı yassı nonkeratinize epitel özelliğindeydi. Bazal membran üzerine oturmuş tek sıralı prizmatik hücrelerin üzerinde 2 veya 3 sıralı poligonal hücreler ve en üstte de 1-2 sıralı yassı hücreler bulunmaktaydı. ikinci katman olan subepiteliyal bazal membran (Bowman membranı, lamina limitans anterior), lamina epithelialis ile corneal stroma tabakası arasında kompakt, asellüler ve kollajenöz matriksden oluşmaktaydı. Cornea'nın en büyük bölümünü oluşturan corneal stroma (substantia propria corneae) tabakasında cornea yüzeyine paralel bir şekilde yerleşmiş kollagen iplik lamelleri tespit edildi. Cornea'nın periferinde daha az oranda elastik ipliklere de rastlandı. Aynı zamanda kollagen iplik lamelleri arasında corneal stroma'nın esas hücreleri olan fibroblastlar (keratoblastlar) gözlendi (Şekil 2). Ince, uzun ve az sitoplazmalı olan bu hücreler metakromazi gösterdikleri için kırmızı pembe renkte görülmekteydi. Corneal stroma'nın hemen altında, stroma'yı lamina endothelium katmanından ayıran sınırlayıcı bir membranın (Descement membran, lamina limitans posterior) bulunduğu belirlendi. Gözün anterior kamarasına bakan cornea'nın kaudal yüzünü, taramalı elektron mikroskobik incelemelerde altıgen şeklinde (Şekil 3) görülen tek katlı yassı epitel hücrelerinin bir araya gelerek oluşturduğu lamina endothelium (Epithelium posterius corneae) katmanının örttüğü tespit edildi. Cornea-scleral bağlantı bölgesinde dallanan ve fenestrasyon gösteren bağ dokudan oluşan lamellerin, aralarında oldukça geniş boşluklar (Fontana yarıkları) bırakarak süngerimsi bir yapıda olan trabeküler ağ meydana getirdiği görüldü (Şekil 2).

Tunica fibrosa bulbi'nin kan damarlarını içeren ve saydam olmayan arka kısmını sclera şekillendirmekteydi (Şekil 1 C-D-E-F).

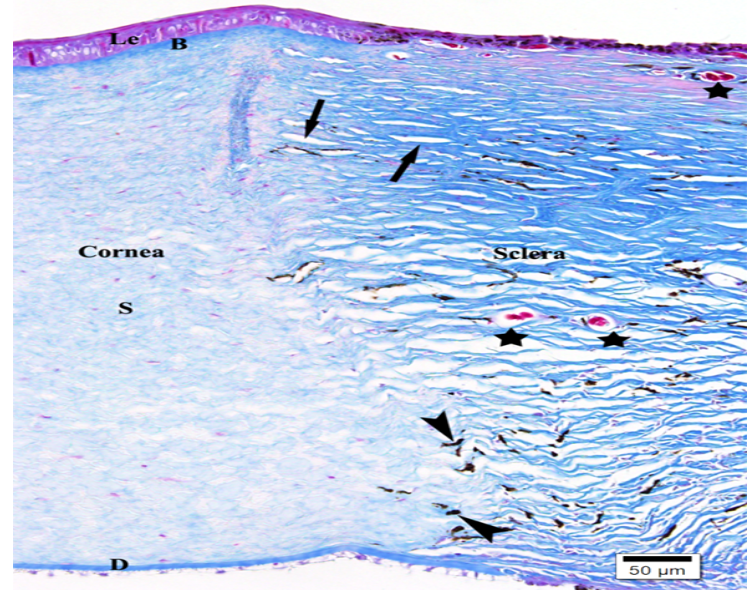

Şekil 2. Cornea-scleral bağlantı bölgesi. Lamina epithelialis (Le), Bowman membranı (B), Stroma (S), Descement membran (D), Melanositler (ok başı), Fontana yarıkları (ok), kan damarları (yıldız).

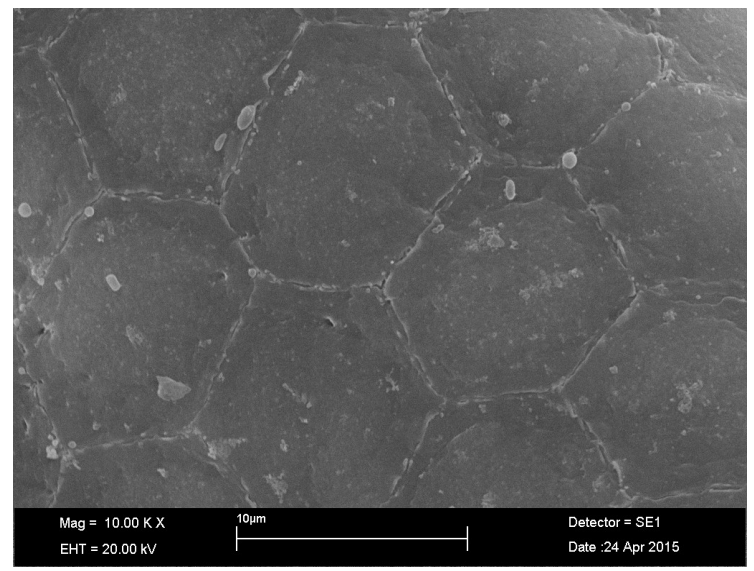

Şekil 3. Cornea'nın ön göz kamarasına bakan arka yüzündeki lamina endothelium tabakasına ait altıgen şeklindeki yassı epitel hücreler

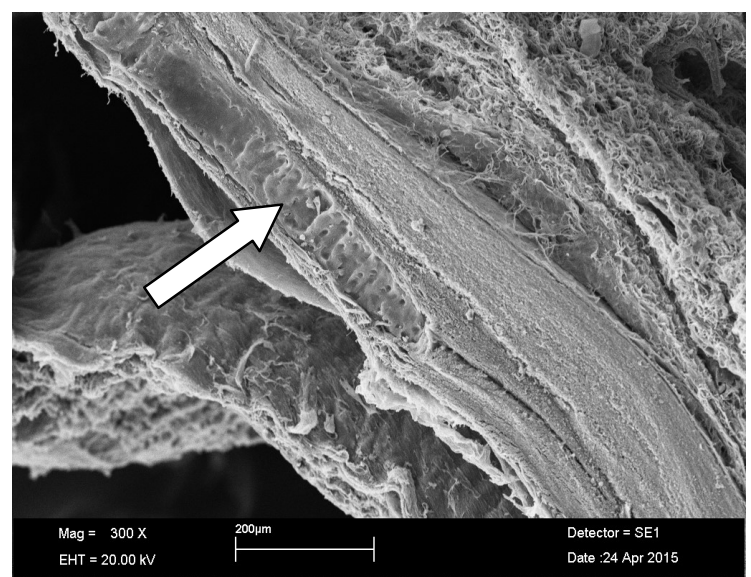

Şekil 4. Sclera kısmında yer alan hiyalin kıkırdak

$\mathrm{Bu}$ katmanda kollagen iplik demetleriyle, bunlar arasına yerleşmiş mekik şekilli fibroblastlar, bol miktarda melanositler ve çok az oranda elastik iplikler tespit edildi. Kollagen iplik demetleri bulbus oculi'nin yüzeyine paralel yerleşim gösterdiği belirlendi. Ayrıca kollagen iplik demetlerinin 
oluşturduğu scleral stroma (Fibröz sclera) içinde ve cornea-scleral bağlantının gerisinde bilateral olarak üst üste yerleşmiş scleral kemiklere rastlandı (Şekil 1D). Bu scleral kemiklerin merkezi kalın, uç kısımları ise daha inceydi. Sclera'nın yaklaşık ön kısmını işgal eden kemiklerin hemen gerisinde, bu bölgeden başlayarak $n$. opticus'un sclera'yı deldiği bölgeye (area cribrosa sclera) kadar uzanan hiyalin kıkırdak (scleral kıkırdak) dokusunun sclera'yı desteklediği gözlendi (Şekil 4). Scleral kıkırdakların, scleral kemiklerde olduğu gibi parçalı ve üst üste binen bir organizasyona sahip olmadığı kesintisiz bir halka şeklinde olduğu belirlendi (Şekil 1 E). Scleral kıkırdak dokunun kesintiye uğradığı $n$. opticus bölgesinde kemik dokunun (os opticus) bulunduğu tespit edildi (Şekil 1 F).

\section{Tartışma ve Sonuç}

Bulbus oculi'nin şeklinin kafa yapısıyla uyumlu olarak yassı kafalı diurnal kanatlılarda yassı, geniş kafalı diurnal kuşlarda küre, nokturnal kuşlarda ise tubular bir yapıya sahip olduğu bildirilmektedir (King ve McLelland, 1984). Nickel ve ark. (1977) ise ördekte bulbus oculi'nin şeklinin kör bir koniye, evcil kuşlarda ise dikey bir elips'e benzediğini belirtmektedir. Yapılan çalışmada equator ve axis bulbi externus uzunlukları değerlendirildiğinde Gerze horoz ve tavuğunda da bulbus oculi şeklinin dikey elips olduğu tespit edilmiştir. Shehan (2012) Basra şehrindeki yerel tavuklarda yapılan gözün anatomik ve histolojik incelenmesi çalışmasında cornea'nın horozlarda uzunluk ve genişliğini sırasıyla $8.3 \pm 0.483 \mathrm{~mm}, 8.4 \pm 0.516 \mathrm{~mm}$ olarak ölçmüştür. Türkiye'nin yerel tavuk ırklarından olan Gerze horozunda ise bu ölçümler sırasıyla $9.28 \pm 0.51 \mathrm{~mm}$, $9.27 \pm 0.53$ olarak bulunmuştur.

Kanatlı hayvanlar bulbus oculi'ye şeklini veren, destekleyen üst üste binmiş kemik plakalar tarafından şekillendirilen halka formunda anatomik bir oluşuma sahiptir (annulus ossicularis sclerae) (Baumell ve ark., 2003; Franz-Odentaal, 2008; Lima ve ark., 2009). Scleral kıkırdağın suda yaşayan hayvanlarda da bulunduğu ve derinliğe bağlı basınç farklılıklarından bulbus oculi'yi koruduğu bildirilmektedir (Brudenall ve ark., 2008). Araştırmamızda da sclera'nın yaklaşık ön kısmını işgal eden kemiklerin hemen gerisinde, bu bölgeden başlayarak n. opticus'un sclera'yı deldiği bölgeye (area sclera cribrosa) kadar uzanan hiyalin kıkırdak (scleral kıkırdak) dokusunun sclera'yı desteklediği gözlenmiştir. Kınalı keklikte cornea'nın epitel hücre katmanının, basit prizmatik hücre katmanı üzerine oturmuş 1-2 sıralı poligonal hücrelerden ve epitel katın en dış sınırını oluşturan yaklaşık 1-2 sıralı yassı hücrelerden oluştuğu bildirilmiştir (Erdoğan ve ark., 2012). Gerze horoz ve tavuğunda ise tek sıralı prizmatik hücrelerin üzerinde 2 veya 3 sıralı poligonal hücreler ve en üstte de 1-2 sıralı yassı hücreler bulunduğu gözlenmiştir. Gündüz avlanan yırtıcı kuşlar, ötücü kuşlar, sinek kuşu ve ağaçkakan gibi türlerde nervus opticus'un etrafında kemikleşmiş U-biçiminde scleral kıkırdağın varlığından bahsetmiştir (King ve Mclelland, 1984). Çalışmamızda scleral kıkırdak dokusunun kesintiye uğradığı n. opticus bölgesinde kemik dokunun (os opticus) varlığı tespit edilmiştir.

Araştırmamızda ülkemizin yerel tavuk ırklarından olan Gerze horoz ve tavuğunun bulbus oculi'sinin tunica fibrosa bulbi katmanı anatomik, histolojik ve elektron mikroskobik olarak incelenmiş ve özellikleri ortaya konulmuştur. Daha önce böyle bir çalışmanın yapılmamış olması bu eksikliği gidermiş bundan sonra yapılacak olan diğer çalışmalara da veri teşkil edeceği düşünülmüştür.

\section{Kaynaklar}

Anonim, 2004: Resmi Gazete (25668 sayllı resmi gazetede yayınlanan tescil 2004/39 nolu tebliğin ek: 19).

Brooke ML, Hanley S, Laughlin SB, 1999: The scaling of eye size with body mass in birds. Proc Biol Sci, 266, 405-412.

Brudenall DK, Schwab IR, Frisches KA, 2008. Ocular morphology of the Leatherback sea turtle (Dermochelys coriacea). Vet Ophtalmol, 11, 99-110.

Crossman G, 1937: A modification of Mallory's connective tissue stain with a discussion of the principles involved. Anat Rec, 69, 33-34.

Dursun N, Türkmenoğlu i, 2002: Duyu organları. In: Dursun, N. (Ed), Evcil Kuşların Anatomisi. 1. baskı, Medisan Yayınevi, Ankara.

Erdoğan S, Akbalık ME, Sağsöz H, 2012. Kınalı Keklikte (Alectoris chukar) Tunica Fibrosa Bulbi'nin Morfolojik Özelliklerinin Araştırılması. F Ü Sağ Bil Vet Derg, 26(2), 65-71.

Franz-Odendaal TA, 2008: Toward understanding the development of scleral ossicles in the chicken, Gallus gallus. Dev Dynam, 237, 3240-3251.

Glasser A, Troilo D, Howland HC,1994:The mechanism of corneal accommodation in chicks. Vision Res, 34, 1549-1566.

Gültiken ME, Onuk B, Yıldız D, Yılmazer B, 2011: Şahinde (buteo buteo) bulbus oculi ve intraorbital kasların (musculi bulbi) morfolojik incelenmesi. Ankara Üniv Vet Fak Derg, 58, 223-228.

King AS, McLelland J, 1984: Special sense organs. In: King AS, McLelland J, editors. Birds: Their structure and function, 2nd ed. London: BaillieeeTindall, 284-314.

Lima FC, Vieira LG, Santos ALQ, De Simone SBS, Hirano LQL, Silva JMM, Romão MF, 2009: Anatomy of the scleral ossicles in brazilian birds. Braz J Morphol Sci, 26, 165-169.

Murphy CJ, Glasser A, Howland HC, 1995: The anatomy of the ciliary region of the chicken eye. Invest Ophthalmol Vis Sci, 36, 889-96.

Nelson NM, 1942: The sclerotic plates of the White leghorn chicken. Anat Rec, 84(3), 295-306. 
Nickel R, Schummer A, Seiferle E, 1977: Anatomy of the Domestic Birds. Verlg Paul Parey, Berlin- Hamburg.

Nomina Anatomica Avium, 1993: International Committee on Avian Anatomical Nomenclature, Handbook of Avian Anatomy:, 2nd. ed. Nuttall Ornithological Club: Cambridge: Mass., USA.

Schaeffel F, Howland HC,1987: Corneal accommodation in the chick and pigeon. J Comp Physiol A, 160, 375384 .
Shehan NA, 2012: Anatomical and histological study of eye in local chickens (Gallus domesticus) at Basrah city. Al- Qadisiya Journal of Vet Med Sci, 11(2), 5359.

*Yazışma Adresi: Burcu ONUK

Ondokuz Mayıs Üniversitesi, Veteriner Fakültesi, Anatomi Anabilim Dalı, 55139, Samsun, Türkiye

e-mail: burcuonuk@omu.edu.tr 